\title{
O DEVIR E O LUGAR DA FILOSOFIA: ALGUNS ASPECTOS DA RECEPÇÃO E DA CRÍTICA DE NIETZSCHE AO IDEALISMO TRANSCENDENTAL VIA AFRIKAN SPIR
}

\author{
William Mattioli* \\ william.mattioli@gmail.com
}

\begin{abstract}
RESUMO A recepção de Nietzsche da filosofia transcendental de Kant é intermediada por diversos autores de diferentes tendências filosóficas que se viam em continuidade com o projeto kantiano de uma filosofia crítica. Um desses autores é Afrikan Spir, filósofo que levou a cabo um programa de renovação da filosofia crítica que ia na contramão da tendência hegemônica na segunda metade do século XIX de naturalização do kantismo. A influência de Spir na construção de algumas das teses epistemológicas centrais do pensamento de Nietzsche é variada, assim como sua importância no que tange à recepção e à crítica nietzscheana ao idealismo transcendental. Nietzsche se apropriou e reinterpretou várias teses e temas presentes na reformulação da teoria kantiana do transcendental proposta por Spir. O objetivo do presente trabalho é investigar o alcance e a importância dessa apropriação e suas consequências para a crítica de Nietzsche ao transcendentalismo. Esta crítica é formulada a partir do pensamento do devir, que constitui a base do seu programa de uma filosofia histórica.
\end{abstract}

Palavras-chave Spir, Kant, idealismo transcendental, tempo, cognição, representação.

* Doutorando do Programa de Pós-Graduação em Filosofia da Universidade Federal de Minas Gerais e membro do GruNie (Grupo-Nietzsche da UFMG). Artigo recebido em 27/07/2013 e aprovado em $14 / 11 / 2013$. 
ABSTRACT Nietzsche's reception of Kant's transcendental philosophy is mediated by various authors from different philosophical tendencies who saw themselves in continuity with the kantian project of critical philosophy. One of these authors is Afrikan Spir, a philosopher who undertook a program of renovation of critical philosophy that went against the tendency of naturalization of kantianism which was hegemonic in the second half of the 19th century. Spir's influence on some of Nietzsche's central epistemological theses is variegated, as well as his importance concerning Nietzsche's reception and criticism of transcendental idealism. Nietzsche appropriated and reinterpreted many theses and themes that featured Spir's reformulation of Kant's theory of the transcendental. The objective of this paper is to investigate the reach and the importance of this appropriation and their consequences for Nietzsche's criticism of transcendentalism. This critique is formulated on the basis of the thought of becoming, which provides, on its part, the basis for his program of a historical philosophy.

Keywords Spir, Kant, transcendental idealism, time, cognition, representation.

\section{I}

A segunda metade do século XIX alemão foi palco de uma importante disputa entre correntes de pensamento que dizia respeito às condições de legitimação tanto da atividade intelectual de modo geral quanto de nossos empreendimentos cognitivos tomados particularmente. O cerne dessa disputa era a questão acerca de qual seria o método mais legítimo e mais adequado à pesquisa da verdade. Após a derrocada dos grandes sistemas filosóficos do idealismo, particularmente após a morte de Hegel, ${ }^{1}$ grande parte dos olhares se voltou para as ciências empíricas à procura da autoridade capaz de sancionar epistemicamente nossos empreendimentos cognitivos, fazendo do materialismo a principal corrente de pensamento da época. Com isso, a filosofia se viu diante da imensa tarefa de recuperar sua dignidade por meio da delimitação de seu objeto de reflexão e do método específico a ser empregado em suas análises, assegurando assim seu lugar no espaço das atividades intelectuais, que se via ameaçado pelo avanço implacável das ciências naturais.

1 Para uma análise mais detalhada do contexto em questão, cf. Lopes (2011, pp. 313-318) e a literatura ali referida. 
A grande estratégia encontrada pela filosofia acadêmica da época consistiu em revisitar a filosofia de Kant, cujo núcleo crítico havia sido obscurecido pelas sombras especulativas lançadas sobre ela pelo idealismo pós-kantiano, e buscar estabelecer com isso uma relação menos hostil e mais saudável entre reflexão filosófica e investigação empírica, já que aqueles sistemas especulativos haviam criado um abismo quase intransponível entre filosofia e ciência. Mas o caminho de retorno a Kant encontrou bifurcações. Se, por um lado, houve um movimento (quase hegemônico nas primeiras décadas da segunda metade do século XIX) de reconciliação que buscava assimilar o materialismo ao kantismo mediante uma naturalização dos seus aspectos transcendentais (movimento levado a cabo não só por filósofos, mas também por cientistas da época), houve, por outro lado, uma tentativa de renovação da filosofia transcendental que apostava todas as fichas na especificidade da reflexão filosófica e do seu método, em contraposição aos métodos das ciências naturais, e que visava portanto não uma assimilação do materialismo, mas uma compartimentalização dos saberes que resguardava à análise autorreflexiva a prioridade de método no âmbito das investigações epistemológicas. Contudo, isso não teria como consequência uma manutenção da relação hostil que vigorava então entre filosofia e ciência: uma vez que seus âmbitos estariam delimitados, assim como seus objetos, elas poderiam se complementar em vez de se atacarem. Essa era a posição defendida pelo filósofo Afrikan Spir.

A tentativa de reformulação e renovação da filosofia crítica levada a cabo por Afrikan Spir numa perspectiva rigorosamente transcendentalista se movia então na contramão daquela tendência hegemônica de naturalização da filosofia transcendental kantiana. Podemos identificar como importantes representantes dessa tendência naturalista filósofos e cientistas como Friedrich Albert Lange e Hermann von Helmholtz, mas ela remonta em certa medida à reapropriação feita por Schopenhauer das teses do idealismo transcendental de Kant. Um dos aspectos centrais desse movimento teórico de naturalização do transcendental é a proposição de uma continuidade de método entre investigação científica e análise filosófica, que pretende eleger a primeira como único meio adequado para a descoberta dos elementos a priori da cognição. Ou seja, os adeptos desse movimento, apesar de assumirem a tese kantiana acerca da existência de elementos a priori que condicionariam a experiência, rejeitam o método de análise transcendental baseado na autorreflexão do sujeito. Para Lange, a descoberta e o exame dos elementos que condicionam universalmente a experiência e que não derivam dela só pode se dar pela via da própria experiência e com base nos recursos atuais da ciência, sobretudo 
da fisiologia da percepção. ${ }^{2}$ Esta última representava um dos mais importantes ramos da ciência empírica da época.

A tese mais influente em voga neste contexto, defendida então principalmente pelo já mencionado fisiólogo kantiano Hermann von Helmholtz, era de que o mundo que conhecemos, o mundo dos fenômenos, é o resultado de operações de natureza inferencial efetuadas inconscientemente pelos órgãos dos sentidos. Conhecida como tese das inferências inconscientes, esta explicação dos processos cognitivos que estão na base de nossa percepção do mundo remonta à tese schopenhaueriana do caráter intelectual da intuição. De acordo com esta explicação, a percepção sensível se funda numa operação inconsciente que consiste em inferir do efeito ou estímulo sentido pelos órgãos sensoriais a causa dessa sensação, a qual é associada a um objeto no mundo. É neste processo que o objeto identificado como causa das impressões é intuído enquanto tal. Para Helmholtz, que defendeu esta tese com base numa série de experimentos empíricos relativos à energia específica de cada órgão e à sua reação aos estímulos externos, aquela operação tem a mesma natureza de uma dedução lógica. E isto "na medida em que extraímos do efeito observado sobre nossos sentidos a representação de uma causa desse efeito, enquanto, de fato, só podemos perceber diretamente as excitações nervosas, isto é, sempre apenas os efeitos, nunca os objetos externos." "3 Assim, a explicação fisiológica acerca de como formamos uma imagem do mundo empírico remete a uma aplicação inconsciente do princípio de causalidade a partir da qual os órgãos sensíveis referem toda sensação a um objeto, projetado exteriormente e percebido então como sua causa. A tese em questão, portanto, implica, por um lado, a validade universal e a priori do princípio de causalidade, um princípio mental entendido como fundamento lógico da percepção; por outro, porém, ela converte essa função lógica numa função psicofisiológica, pois não se trata mais, como em Kant, de um entendimento puro que aplica espontaneamente um conceito às impressões recebidas passivamente pela sensibilidade, mas, antes, são os próprios órgãos sensoriais e a estrutura psicofísica a eles associada que operam de modo inferencial interpretando causalmente as impressões sensíveis. Sendo assim, a fisiologia da percepção, na medida em que se ocupa dessa organização psicofísica (para usar o termo empregado por Lange), seria a via mais adequada para a descoberta dos princípios a priori da cognição.

Spir, em sua tentativa de reformulação da filosofia crítica e de restauração de uma perspectiva transcendentalista mais robusta, critica esta tese por meio de três argumentos: 
1) em primeiro lugar, ela estaria em desacordo com o sentido do próprio princípio de causalidade. Para Spir, o que está implicado no princípio de causalidade é que nenhuma mudança pode ocorrer sem que outra mudança a preceda no tempo e à qual ela se segue segundo uma lei fixa. Ou seja, ao estabelecer a causa de uma mudança, nos depararemos sempre com outra mudança, nunca com um objeto ou uma substância. ${ }^{4}$ Para compreender melhor este argumento, é preciso ter em mente a dedução do conceito de causalidade proposta por Spir. Podemos dividir sua argumentação em dois passos:

a) segundo o autor, o conceito de causalidade é derivado do princípio de identidade, princípio entendido por ele como lei fundamental do pensamento e como único elemento legitimamente a priori do sujeito cognoscente. Conforme este princípio, "todo objeto em si, segundo sua essência própria, é idêntico a si mesmo". ${ }^{5}$ Em última instância, este conceito do "idêntico a si mesmo" coincide com o conceito de incondicionado, ao qual correspondem as noções de Ser e substância. Neste sentido, conforme nosso conceito de substância, a "identidade consigo mesmo" seria o estado originário, essencial e incondicionado de todo objeto em si. A mudança, por sua vez, segundo Spir, significa "uma não identidade ou não conformidade consigo mesmo daquilo que muda" ${ }^{6}$ Por conseguinte, ela não pode pertencer à essência incondicionada do objeto, à qual deve corresponder uma identidade absoluta. Assim, toda mudança deve ser condicionada, a saber, por algo exterior ao próprio objeto, algo que não é o objeto mesmo: "e isto é exatamente o que o princípio de causalidade declara: nenhuma mudança sem causa". ${ }^{7}$ Portanto, para Spir, o conceito de causalidade deve ser entendido como resultado da aplicação do conceito originário e a priori da essência íntima de cada coisa, "que encontra sua expressão no princípio lógico da identidade", ao "fato da mudança, que só pode ser conhecido a partir da experiência";

b) dado que toda mudança é portanto condicionada, é inconcebível que esta possa emergir do estado de repouso que caracteriza a essência incondicionada de cada objeto. Nesse sentido, nenhuma substância, segundo sua essência, pode ser causa, pois toda causação implica condicionalidade. Desse modo, segundo Spir, a partir do estado originário da identidade a 
si nenhuma mudança pode ter origem. Disso se segue, por sua vez, que a causa de uma mudança, isto é, seu condicionante, só pode ser outra mudança, nunca uma substância ou um objeto. É por isso que Spir afirma que a tese das inferências inconscientes, ao explicar a percepção de um objeto empírico como um ato de intuição de uma causa externa das impressões, está em contradição com o próprio princípio de causalidade; 2) em segundo lugar, a tese das inferências inconscientes estaria em contradição com a natureza imediata do conhecimento dos corpos. $\mathrm{Na}$ medida em que explica nossa percepção dos objetos empíricos e, portanto, nossa crença na existência do mundo exterior, a partir da aplicação de uma regra inferencial de natureza lógica, esta tese não seria capaz de explicar a força persuasiva, a certeza intuitiva e a imediaticidade da nossa apreensão do mundo fenomênico. Ou seja, ela não seria capaz de explicar o fato de que a realidade é representada em nossa consciência de modo absolutamente imediato e com uma força de persuasão fenomenologicamente irresistível. Na qualidade de uma regra hipotética, o princípio de causalidade só poderia nos fornecer um conhecimento teórico-discursivo acerca do mundo exterior - como o conhecimento que temos acerca das relações causais entre os fenômenos -, jamais um conhecimento intuitivo imediato dos próprios fenômenos. Este último pressupõe uma norma cognitiva categórica que afirma incondicionalmente a substancialidade do mundo ao aplicar o conceito de objeto como substância (derivado do princípio lógico de identidade) às impressões sensíveis, interpretando essas impressões como qualidades diversas de um mesmo objeto ontologicamente autônomo. Nesse sentido, o princípio de identidade atua também como discriminante ontológico, pois estabelece a norma a priori para a determinação e fixação do conteúdo factual da representação enquanto objeto empírico, garantindo assim objetividade à experiência. $\mathrm{O}$ caráter incondicional dessa lei do sujeito cognoscente e de sua aplicação é o que, para Spir, explica a imediaticidade da certeza que temos da existência do mundo exterior, de modo que o princípio de causalidade está a ela subordinado;

3 ) por fim, esta teoria fisiológica da percepção, ao reconduzir o princípio cognitivo que determina nossa apreensão do mundo a uma função orgânica que pode ser estudada pelas ciências empíricas, desconheceria o estatuto particular da afirmação envolvida no processo de representação, cuja natureza fundamentalmente lógica não se deixaria explicar por meio de leis físicas. Para Spir, leis físicas (fisiológicas) podem explicar certas operações psicológicas de associação, assim como as causas mecânicas da cognição resultantes de nossa organização corporal, mas são incapazes de dar conta 
dos princípios lógicos do conhecimento. Um princípio ou lei do conhecimento é uma disposição interna do sujeito a "referir a objetos o conteúdo que lhe é dado" e, segundo a natureza desse conteúdo, formar juízos acerca da existência e da natureza dos objetos. Spir define as leis lógicas envolvidas na cognição como "princípios gerais de afirmações sobre objetos, isto é, uma necessidade interna de ter uma crença acerca dos objetos". Uma tal disposição jamais poderia ser produto de causas físicas: "a este tipo de leis chamamos leis lógicas, e estas são, segundo sua essência mais íntima, distintas das leis físicas objetivas às quais pertencem também as leis da associação." "Essas leis de associação são secundárias com relação à lógica judicativa de aplicação do conceito de substância às sensações. Enquanto um processo como o das inferências inconscientes poderia ser explicado fisicamente a partir de um vocabulário fisiológico (incluindo-se o psicológico ou associativo), o fato da consciência, que é acompanhado da evidência fenomenológica da existência de corpos fora de nós (ou do sentimento de evidência, mesmo que sua correspondência objetiva seja falsa), só pode ser explicado por um esquema lógico-judicativo que transcende a constituição biológica do homem. Trata-se no fim das contas de um esquema lógicometafísico do qual Spir retirará implicações ontológicas. É sobretudo com relação a este ponto que o programa de Spir de renovação da filosofia crítica mais se distancia da tendência hegemônica na segunda metade do século XIX alemão de naturalização do transcendental. Ele resguarda, na cognição, um espaço lógico irredutível ao âmbito de explicação dos modelos das ciências naturais, conservando assim um método de investigação específico para a filosofia, que concerne ao que poderíamos chamar hoje de espaço lógico-normativo das razões, diferentemente das ciências naturais, que se ocupa com o espaço físico-descritivo das causas: ${ }^{10}$

\footnotetext{
Disso resulta uma relação inteiramente diferente entre ciência da natureza e filosofia, na qual ambas se complementam mutuamente ao invés de se atacarem. Pois onde termina o território de uma, somente ali se inicia o da outra. A ciência natural não pergunta por exemplo por que e de que modo nós extraímos, do conteúdo de nossa própria consciência, o conhecimento de um mundo corpóreo exterior a nós. A ciência da natureza tampouco pode responder a essa pergunta, uma vez que ela tem o conhecimento do mundo corpóreo como seu pressuposto último e supremo; todavia cabe à filosofia responder a essa questão, na medida em que, com este propósito, ela remonta àquilo que é imediatamente certo. ${ }^{11}$
}

9 Spir, 1877, I, p. 76.

10 Cf. a esse respeito Clark e Dudrick (2006, pp. 159-160).

11 Spir, 1877, I, p. 32. 


\section{II}

A influência de Afrikan Spir na construção de algumas das teses epistemológicas centrais do pensamento de Nietzsche é variada, assim como sua importância no que tange à recepção e à crítica nietzscheana ao idealismo transcendental de cunho kantiano. Nietzsche se apropriou e reinterpretou várias teses e temas presentes na reformulação da teoria kantiana do transcendental proposta por Spir. Alguns dos aspectos centrais desse projeto de reelaboração teórica são, por um lado, a recondução do a priori a um único elemento constitutivo, o princípio de identidade, o qual nos forneceria o conceito de Ser e de incondicionado e, por outro, a afirmação de uma extensão ontológica desse conceito. Além disso, Spir serviu a Nietzsche como porta de acesso a uma problemática que envolvia tanto o diálogo entre teoria do conhecimento e ciência natural quanto as interfaces entre epistemologia, ontologia e metafísica. Assim, ele forneceu a Nietzsche uma análise sistemática das principais teorias científicas e epistemológicas da época, trazendo à luz ao mesmo tempo um conjunto de pressupostos teóricos do transcendentalismo que Nietzsche irá associar criticamente a um comprometimento ontológico com o conceito normativo de Ser de cunho parmenidiano. Spir é, por essa razão, um dos filósofos que serviram de base para a interpretação do jovem Nietzsche dos pré-socráticos, que visava confrontar seus pensamentos com certas posições contemporâneas tanto da ciência quanto da filosofia. É sobretudo sua interpretação e crítica do pensamento de Parmênides em contraposição ao heraclitismo que é mais devedora do quadro conceitual tomado de empréstimo de Spir na sua reformulação da filosofia crítica. Com efeito, Parmênides é identificado por Nietzsche como o precursor de uma ontologia cujos pressupostos normativos e consequências teóricas conduziriam a uma crítica epistemológica radical que, por sua vez, teria encontrado na filosofia transcendental kantiana sua expressão mais acabada. Em contrapartida, Heráclito é visto como o precursor de um tipo de filosofia histórica essencialmente antitranscendentalista que, aliada aos resultados da investigação científica, nos colocaria diante do problema do conhecimento com um olhar mais pessimista. ${ }^{12}$

12 Mesmo que o programa de uma filosofia histórica aliada às ciências empíricas e sua contrapartida epistemológica articulada em torno da assim chamada "teoria do erro" de Nietzsche sejam trazidos a público somente com a publicação de "Humano, demasiado humano" em 1878, a posição filosófica fundamental subjacente a esse programa, que tem sua inspiração na intuição heraclitiana do devir e que encontra respaldo nos resultados das ciências empíricas da época, já está presente nas primeiras análises nietzscheanas acerca dos filósofos pré-socráticos, presentes tanto em suas lições sobre os filósofos pré-platônicos quanto no texto sobre a filosofia na época trágica dos gregos. A esse respeito, cf. Meyer, 2012. 
Mas, antes de entrarmos mais especificamente nessa discussão, presente sobretudo no texto "A filosofia na época trágica dos gregos", de 1873, e que antecipa alguns aspectos centrais da posterior teoria do erro de Nietzsche, ${ }^{13}$ é útil nos debruçarmos sobre o fragmento 19[242] de 1872. Trata-se de uma das primeiras anotações escritas sob influência da leitura de Spir. Neste fragmento, Nietzsche retoma uma discussão de Spir acerca dos juízos sintéticos, reinterpretando-a e chegando à conclusão de que os processos que estão na base de nossa cognição são de natureza ilógica e implicam o caráter ficcional e antropomórfico do conhecimento.

$\mathrm{Na}$ passagem retomada por Nietzsche no fragmento em questão, Spir analisa a natureza dos juízos que fundam nossa representação e nosso conhecimento do mundo empírico. Para ele, a representação que possuímos de um mundo exterior preenchido por corpos só é possível por meio da aplicação de um princípio cognitivo a priori que age categorialmente sobre todo conteúdo sensível fixando-o como identidade e unidade. Este princípio, identificado por Spir com o princípio de identidade, seria o elemento fundamental de organização da experiência, a partir do qual seríamos capazes de estabelecer e identificar objetos empíricos estáveis, compreendidos como substâncias, a partir dos dados sempre instáveis das sensações. Enquanto elemento constitutivo da representação, portanto, o princípio de indentidade, ao estabelecer a norma $a$ priori para a determinação do conteúdo sensível da representação enquanto objeto empírico, garantiria objetividade à experiência, atuando como discriminante ontológico. Contudo, tomado em sua expressão meramente lógica, o princípio de identidade permite apenas juízos tautológicos do tipo $\mathrm{A}=\mathrm{A}$, ao passo que o juízo que nos permite descrever a representação de um objeto empírico, apesar de conter em si uma aplicação categorial do princípio de identidade, é de outra natureza. Nesse sentido, na passagem retomada por Nietzsche no fragmento 19[242] Spir escreve:

Que representação alguém obteria da essência de um lápis, por exemplo, caso se lhe dissesse apenas: o lápis é o lápis? Obviamente nenhuma. Para descrever o lápis, precisaríamos nos expressar mais ou menos assim: o lápis é uma coisa extensa, é alongado, fino, tem forma cilíndrica, é colorido, duro, pesado, etc. Vemos aqui, portanto, toda uma quantidade de qualidades contidas ou abarcadas numa unidade (o lápis), as quais são todas diferentes umas das outras.

Ora, a unidade do diverso é chamada em geral de síntese, e as proposições nas quais a essência de uma tal unidade é expressa são chamadas proposições sintéticas ou 
juízos sintéticos. A fórmula geral das proposições sintéticas, a expressão geral de uma síntese, é a proposição: “A é B". ${ }^{14}$

Spir entende aqui a síntese como momento constitutivo de nossa apreensão do mundo empírico, caracterizado por uma pluralidade de objetos que abarcam uma diversidade de qualidades. É somente por meio de um ato de síntese que somos capazes de perceber qualidades diversas - que correspondem a uma pluralidade de impressões sensíveis no sujeito - como pertencentes a uma mesma coisa, compreendida como unidade deste diverso. A partir da passagem citada é possível vislumbrar o que, para Spir, constitui a condição sob a qual se nos torna possível a experiência de objetos em geral. O objeto, enquanto unidade de qualidades diversas, é o resultado de um juízo sintético no qual certos complexos de sensações são referidos a um substrato. Segundo Spir, este juízo (ou síntese) se funda, em última instância, na lei lógica fundamental do sujeito cognoscente, a qual postula uma substância idêntica a si mesma como suporte das sensações dadas na percepção. Sem a necessidade subjetiva originária de postular objetos incondicionados e que permanecem os mesmos, nenhuma experiência do mundo seria possível. Com efeito, o que de fato percebemos daquilo a que chamamos "objetos" é meramente uma pluralidade de qualidades e atributos ligados por uma certa lei, em conformidade com a qual eles sempre aparecem juntos. Contudo, pensamos um objeto ou um corpo, para além desses complexos de sensações, "como uma unidade individual que é por assim dizer o suporte das qualidades [...] Aqui, o esforço do pensamento é claramente o de apreender as muitas qualidades simplesmente como diversos lados da essência una e indivisível da coisa." ${ }^{15}$ Entre o conceito de substância, derivado imediata e originalmente do princípio de identidade, e a necessidade de representar coisas ou objetos existentes por si mesmos, deve haver então uma relação lógico-predicativa que, por sua vez, corresponde ao quadro judicativo no interior do qual as proposições sintéticas são formadas.

No fragmento 19[242] de 1872, Nietzsche retoma a passagem de Spir citada acima e escreve:

A essência da definição: o lápis é um corpo alongado, etc. A é B. O que é alongado é, aqui, ao mesmo tempo colorido. As qualidades contém apenas relações.

Um corpo determinado é igual tantas e tantas relações. Relações jamais podem ser a essência, mas apenas efeito da essência. O juízo sintético descreve uma coisa segundo seus efeitos, isto é, essência e efeitos são identificados, isto é, uma metonímia. 
Portanto, na essência do juízo sintético jaz uma metonímia, isto é, uma equação falsa.

Ou seja, as inferências sintéticas são ilógicas. Quando as aplicamos, pressupomos a metafísica popular, isto é, aquela que considera efeitos como causas.

O conceito "lápis" é confundido com a "coisa” lápis. O “é” no juízo sintético é falso, ele contém uma transposição, duas esferas distintas são colocadas lado a lado, entre as quais jamais pode ocorrer uma equação.

Vivemos e pensamos sob efeito do ilógico, no não-saber, no falso saber.

Num movimento argumentativo que parece apontar numa direção divergente das intenções teóricas de Spir, que aloca os juízos sintéticos num espaço lógico cuja base é a lei da identidade, Nietzsche, discutindo diretamente com um modelo naturalista da cognição (o modelo das inferências inconscientes) ${ }^{16}$ compreende aqui estes juízos como resultado de uma transposição semântica (metonímica) que corresponde à confusão ou inversão entre essência e efeito. Identificando essa operação semântica a uma equação falsa, Nietzsche conclui que as inferências sintéticas são ilógicas, e isso, ao que parece, por dois motivos: a) primeiramente porque Nietzsche não acredita que o processo fisiológico de transposição de um estímulo nervoso em imagem possa ser descrito em termos lógicos, já que ele ocorre numa esfera da cognição desprovida de signos abstratos e cujas associações analógicas (metafóricas) não possuem uma forma dedutiva-inferencial ou mesmo predicativa, estando aquém de qualquer estrutura lógica ou conceitual; b) em segundo lugar, porque a confusão entre causa e efeito, descrita por Nietzsche como uma metonímia, transgride as regras lógicas e conceituais que estruturam nossa compreensão racional do mundo, correspondendo assim a uma aplicação inadequada do princípio de razão. Ora, é justamente desse modo que o jovem Nietzsche, sob influência do linguista e filósofo Gustav Gerber ("Die Sprache als Kunst"), ${ }^{17}$ compreende o princípio que atua inconscientemente na cognição: como uma operação ilógica, metafórica (metonímica), que confunde impressões subjetivas com qualidades objetivas imanentes a um objeto, e projeta então falsamente este complexo de impressões como um objeto no mundo exterior. A influência de Gerber é aqui clara. Essa é exatamente a definição que o autor de "Die Sprache als Kunst" dá para a figura da metonímia: inversão de causa e efeito, ao associar esse tropo à nossa forma de aplicação do princípio de causalidade, como quando dizemos, por exemplo: "essa bebida é amarga, em vez de: a bebida suscita em nós uma sensação desse tipo"; ou "a pedra é dura, como se 
a dureza fosse outra coisa que um juízo nosso". ${ }^{18}$ Seguindo essa sugestão de Gerber, Nietzsche afirma em "Sobre verdade e mentira":

Deduzir do estímulo nervoso uma causa fora de nós já é o resultado de uma aplicação falsa e injustificada do princípio de razão. [...] como estaríamos autorizados a dizer: a pedra é dura: como se "duro" nos fosse conhecido de outra forma e não simplesmente como uma excitação absolutamente subjetiva! ${ }^{19}$

É ainda nesse contexto que ele escreve no fragmento 19[217] de 1872: "São tropos, não inferências inconscientes, sobre os quais repousam nossas percepções sensíveis". Como vimos, o modelo das inferências inconscientes, que visava explicar os mecanismos fisiológicos que dão origem à percepção sensível, era o modelo em voga na segunda metade do século XIX alemão, cujo ambiente intelectual era marcado por uma forte tendência de naturalização do transcendental que tinha nas ciências empíricas seu referencial metodológico. Friedrich Albert Lange e o fisiólogo kantiano Hermann von Helmholtz eram dois dos principais representantes desse movimento. Afrikan Spir, ao contrário, era um crítico desse modelo e da tendência que ele representava, uma vez que seu projeto de renovação da filosofia crítica partia do pressuposto de que a filosofia deveria se valer de um método próprio de investigação, baseado na análise a priori de nossas funções cognitivas. $\mathrm{O}$ modelo tropológico desenvolvido por Nietzsche no início da década de 1870 sob influência da leitura de Gerber, por sua vez, pretende apresentar uma alternativa à tese das inferências inconscientes, sem contudo escapar a um vocabulário que é em grande medida naturalista.

Segundo esta tese hegemônica na época, nossa imagem do mundo sensível se origina graças a um princípio atuante nos órgãos sensoriais e que seria, em última instância, idêntico àquele que rege nossos juízos lógicos. A explicação se baseia na aplicação da categoria de causalidade para toda sensação imediatamente dada, de forma que nós construímos uma imagem sensível do mundo como fenômeno referindo toda sensação a um objeto e interpretando-o como sua causa. Dado o pressuposto da validade universal e a priori do princípio de causalidade, os órgãos responsáveis pela construção do mundo fenomênico operariam então segundo leis fixas e invariáveis, de forma que sua operação seria acompanhada de necessidade e universalidade. Ao que tudo indica, este é um dos aspectos centrais da tese das inferências inconscientes contra o qual

18 GERBER, G. “Die Sprache als Kunst”. Erster Band. Bromberg, 1871, p. 394, apud Meijers; Stingelin, 1988, p. 357.

19 VM § 1, KSA 1, p. 878. 
Nietzsche faz valer seu modelo tropológico. Ao afirmar que são tropos, não inferências inconscientes, sobre os quais repousam nossas percepções sensíveis, ele parece querer ressaltar que necessidade, universalidade e logicidade são características conceituais interconectadas e que pertencem estruturalmente a um nível de abstração que não corresponde à dinâmica contingente dos processos inconscientes que estão na base da cognição. ${ }^{20} \mathrm{E}$ isso porque aquele columbário conceitual é, para o jovem Nietzsche, um produto tardio da formação de metáforas, sobre cuja base se origina a cognição, e que devem ser descritas como contingentes, individuais e ilógicas. Nesse sentido, Nietzsche entende nossas operações "inferenciais" (projetivas) como operações ilógicas, ou mesmo como falácias, pois elas estão aquém de qualquer estrutura formal e não são justificadas nem justificáveis por regras conceituais de natureza lógica - ao contrário, devido a seu caráter semanticamente arbitrário, elas ferem essas regras. É por isso que no fragmento 19[242], no qual Nietzsche retoma a discussão de Spir acerca dos juízos sintéticos, ele afirma que nós pensamos e vivemos constantemente sob o efeito do ilógico, na medida em que só construímos o mundo fenomênico com base em processos de metaforização que carregam em si uma arbitrariedade semântica incontornável.

Dentro desse contexto, o movimento argumentativo apresentado por Nietzsche nesses fragmentos aponta numa direção divergente dos pressupostos teóricos de Spir na medida em que este último pressupõe uma estrutura formal, um conceito a priori de Ser, do "idêntico a si mesmo", numa esfera da cognição que, segundo a posição do jovem Nietzsche, está aquém de toda forma lógico-predicativa ou conceitual. ${ }^{21}$ Este é o pano de fundo que o autoriza a reconduzir a explicação de Spir acerca dos juízos sintéticos para o interior do seu modelo tropológico.

Entretanto, apesar dessa diferença fundamental entre as posições dos dois autores, um ponto importante de convergência deve ser destacado: trata-se da tese mais geral segundo a qual nosso conhecimento do mundo fenomênico é marcado por uma contradição ou inconsistência lógica. Se para Nietzsche a falsidade e/ou o caráter falacioso e ilógico do nosso conhecimento são resultado de uma transposição (Übertragung) metonímica na qual duas esferas distintas são equacionadas - a esfera da "coisa" e a esfera das qualidades e relações -, de modo que causa e efeito são confundidos e a coisa é definida a partir da soma de suas propriedades, para Spir o julgamento sintético, no qual

20 Cf. a esse respeito Mattioli, 2010, pp. 54-55.

21 Cf. VM § 1 (KSA 1, pp. 881-882 e p. 884) e o fragmento N 1872 19[78]. Ver ainda a passagem sobre a origem do nosso conceito de Ser em FTG § 11, KSA 1, p. 847. 
qualidades diversas são atribuídas a um mesmo objeto, está em conflito com as leis lógicas da autoidentidade e da não contradição. ${ }^{22}$ Como vimos, segundo Spir, todo objeto empírico, enquanto unidade sintética de uma multiplicidade de qualidades, é o produto da aplicação do nosso conceito de substância aos complexos de sensações, com o que as diversas qualidades correspondentes às sensações são atribuídas a um substrato. Nosso conceito de substância, por sua vez, coincide com o conceito de incondicionado, expressão mais imediata da norma epistêmica que rege nosso pensamento: o princípio de identidade. Mas o incondicionado, enquanto tal, não pode conter multiplicidades, pois multiplicidade implica relação (a relação das múltiplas qualidades entre elas), e relação implica condicionalidade. Nietzsche parece se referir a este argumento ao afirmar que qualidades contêm apenas relações e que relações jamais podem ser a essência, chegando à conclusão de que o "é" no juízo sintético, ao definir a "coisa" pelas suas propriedades, equacionando duas esferas distintas entre as quais jamais pode haver uma equação, é falso e/ou ilógico. ${ }^{23}$

Retomando o argumento de Spir, podemos dizer então que nosso conhecimento do mundo empírico, na medida em que é necessariamente um produto de juízos sintéticos, é logicamente inconsistente, pois pressupõe a aplicação do conceito de incondicionado (do absolutamente idêntico a si mesmo) à multiplicidade da experiência, na qual ele nunca pode ser plenamente instanciado: "Pensemos num objeto incondicionado A, cuja essência consiste em duas qualidades $a$ e $b$; nesse caso, A é tanto $a$ quanto $b$ e nada além de $a$ e $b$. Porém, uma vez que $a$ e $b$ são diferentes um do outro, o objeto A seria, assim, na medida em que é a qualidade $a$, diferente de si mesmo na medida em que é a qualidade $b .{ }^{\prime 24}$

Sendo assim, o incondicionado pressuposto pela norma do pensamento, o princípio de identidade em sua forma mais pura, deve se referir a uma unidade absolutamente simples que só poderia ser instanciada por um ente tal como o Ser de Parmênides. Para Spir, um tal ente existe realmente. Segundo ele, o desacordo entre o conceito de incondicionado, por um lado, tal como é expresso pelas leis lógicas da identidade e não contradição, e a natureza empírica dos corpos, por outro, nos remete necessariamente a um lado da realidade para além do âmbito sensível no qual este conceito seria instanciado: trata-se daquilo que ele identificará com a coisa em si kantiana, a essência própria das coisas. 
O procedimento de Spir pode ser visto aqui como uma espécie de "inversão" do pressuposto básico tanto da Analítica quanto da Dialética Transcendental kantiana segundo o qual os conceitos puros só podem ser legitimamente aplicados aos objetos da experiência, isto é, aos fenômenos, jamais à coisa em si. É justamente por meio desta limitação do uso dos conceitos a priori que Kant busca resolver as antinomias da razão. Para Spir, ao contrário, a única aplicação legítima do conceito a priori do nosso pensamento - o conceito de substância ou de incondicionado - é sua aplicação à coisa em si, pois ao ser aplicado à pluralidade e transitoriedade dos objetos empíricos ele implica uma contradição lógica com estes. ${ }^{25} \mathrm{Com}$ isso, Spir sustenta uma ontologia de cunho parmenidiano ao identificar a coisa em si à instanciação do nosso conceito de Ser. O elemento a priori do pensamento, o princípio lógico da identidade, possui assim uma extensão ontológica, de modo que o conceito de incondicionado nos forneceria a única representação adequada da essência da realidade: "não pode haver outra ordenação justificada do pensamento a não ser aquela que nos capacita e nos conduz ao conhecimento correto da realidade". ${ }^{26}$

\section{III}

A proximidade entre os pressupostos e consequências teóricas da filosofia transcendental de Spir (assim como da de Kant, em alguns de seus pontos centrais), por um lado, e o pensamento de Parmênides, por outro, não passou despercebida aos olhos de Nietzsche. É por isso que as reflexões e os argumentos do renovador da filosofia crítica são tomados como pano de fundo para a apresentação das teses de Parmênides no interior do diálogo mais ou menos implícito estabelecido pelo jovem Nietzsche entre os pré-socráticos e seus contemporâneos. Como sugere Paolo d'Iorio, ${ }^{27}$ o primeiro ponto de aproximação entre os dois filósofos é o anseio pela certeza, cuja busca, no caso de Parmênides, teria conduzido a um reino de abstrações lógicas totalmente estranho ao espírito grego. ${ }^{28}$ Este é um tema-chave em Spir, que acredita que

25 Cf. a esse respeito Riccardi, 2009, pp. 71-72.

26 Spir, 1873, I, p. 165. Cf. ainda a seguinte passagem: "É ainda claro que o princípio de identidade enuncia uma afirmação geral sobre a natureza dos objetos reais; portanto, ele também não pode ser outra coisa senão a expressão de um conceito geral da essência dos objetos ou da realidade. Se esta não é a realidade empírica, consequentenemte é uma outra. Evidenciando-se que o conceito do 'idêntico a si mesmo' é o mesmo que o conceito do incondicionado, do 'existente por si mesmo', então o princípio de identidade se referirá portanto ao incondicionado, ao noumenon, à coisa em si ou ao objeto transcendental que subjaz à nossa experiência" (ibidem, p. 198).

27 Cf. D'lorio, 1993, pp. 262-263.

28 Cf. FTG $\S 11, \mathrm{KSA} 1$, p. 845. 
toda filosofia deve ter como ponto de partida certezas imediatas, de natureza factual e racional. No que concerne àquilo que Nietzsche reconhecerá como sendo o ponto fundamental tanto da ontologia quanto da crítica de nosso aparato cognitivo presentes na filosofia de Parmênides, o papel central será concedido à certeza imediata de caráter racional, identificada por Spir ao princípio lógico da identidade: "a única forma do conhecimento em que acreditamos incondicionalmente e cuja negação equivale à loucura é a tautologia $\mathrm{A}=\mathrm{A}$ " ${ }^{29}$

A partir dessa certeza e verdade lógicas, Parmênides teria chegado à conclusão de que somente o Ser enquanto identidade pura, isto é, o que pode ser expresso por uma proposição tautológica do tipo $\mathrm{A}=\mathrm{A}$, existe realmente: $o$ Ser é! Na medida em que nos vemos obrigados a atribuir qualidades ao Ser e dizer algo do tipo: $\mathrm{A}=\mathrm{B}$ (o que equivale a dizer $\mathrm{A}=$ não $\mathrm{A}$ ), encontramonos no erro. É possível reconhecer aqui as reflexões de Spir discutidas acima acerca dos juízos sintéticos e sua concepção do caráter ilógico do nosso conhecimento empírico. A diversidade e a mudança das qualidades comportam diferenças, ou seja, negação da identidade, de modo que aquilo a que se pode atribuir mudança e diversidade, todo o mundo sensível, portanto, pertenceria, segundo o Parmênides de Nietzsche, ao âmbito do não Ser: "tudo aquilo de que se pode dizer: 'foi' ou 'será' não é; do Ser, porém, jamais se pode dizer: "não é"". ${ }^{30}$ Com esse pensamento, ele teria realizado a primeira e mais importante crítica do nosso aparato cognitivo, cindindo assim o âmbito da sensibilidade (da temporalidade, da mudança e da diversidade) e o âmbito das abstrações lógicas (do princípio lógico da identidade, do Ser uno, eterno e atemporal), cisão que encontraria sua formulação mais precisa na distinção kantiana entre sensibilidade e entendimento puro. A consequência dessa "crítica fatal" é a seguinte:

Todas as percepções sensíveis, julga Parmênides, fornecem apenas ilusões; e sua ilusão principal é justamente que elas nos fazem crer que também o não Ser é, que também o devir tem um ser. Toda aquela pluralidade e aquele colorido do mundo conhecido pela experiência, a mudança de suas qualidades, a ordem em sua ascensão e declínio é impiedosamente descartada. ${ }^{31}$

Desse modo, Nietzsche vê na filosofia de Parmênides os prelúdios tanto de uma crítica epistemológica radical quanto da ontologia. Uma vez que a experiência não nos mostra nenhum ente que corresponda ao nosso conceito 
normativo de Ser, Parmênides teria deduzido que esse conceito, por estar presente em nosso pensamento, deve necessariamente poder ser instanciado numa dimensão ontológica que ultrapassa a experiência. $\mathrm{O}$ conteúdo lógico do pensamento e seu valor de verdade não teriam portanto nenhuma referência à experiência, mas viriam de outro lugar, a saber, de um mundo suprassensível ao qual nós teríamos um acesso direto pelas vias do pensamento puro. ${ }^{32} \mathrm{O}$ argumento atribuído por Nietzsche a Parmênides é aqui análogo ao argumento de Spir segundo o qual o desacordo entre nosso conceito de incondicionado e a natureza empírica dos corpos nos remeteria necessariamente a um lado da realidade para além do âmbito sensível que corresponderia a esse conceito.

\section{IV}

Nos parágrafos que se seguem, Nietzsche mobiliza um importante argumento contra a tese parmenidiana de uma identidade entre pensamento e Ser supostamente capaz de nos assegurar da existência de uma dimensão ontológica essencial e incondicionada para além do mundo sensível. Trata-se do argumento (atribuído por Nietzsche sobretudo a Anaxágoras) da mobilidade e do caráter temporal do próprio pensamento. Se o Ser deve ser entendido como uma unidade incondicionada, imutável e atemporal, o pensamento, para ser idêntico a essa unidade e poder apreendê-la verdadeiramente, deveria ter essas mesmas características. Porém, "é totalmente impossível caracterizar o pensamento como uma permanência invariável, como um pensar-a-si-mesmo eternamente imóvel da unidade". ${ }^{33} \mathrm{O}$ pensamento é sempre necessariamente um movimento de conceitos e uma sucessão de representações que se dá incontornavelmente no tempo. Eis o que os adversários de Parmênides poderiam lhe objetar, recorrendo a um argumento ad hominem e afirmando que no seu próprio pensamento há sucessão e movimento, razão pela qual esse pensamento não poderia ser real e portanto nada poderia provar acerca do real.

Lançando mão de um argumento que retoma em algumas linhas gerais a referência à filosofia transcendental de Kant presente em seu escrito sobre os filósofos pré-platônicos, ${ }^{34}$ Nietzsche recorre à tese kantiana da idealidade transcendental do tempo e do fenomenismo da experiência interna para propor uma saída a este embaraço filosófico no qual os adversários de Parmênides o teriam lançado. Àquela objeção, Parmênides poderia responder, como Kant, 
da seguinte forma: "é verdade que eu posso dizer que minhas representações se sucedem umas às outras: mas isso significa apenas que somos conscientes delas numa sequência temporal, isto é, segundo a forma do sentido interno. $\mathrm{O}$ tempo não é, por isso, algo em si, tampouco uma determinação objetivamente inerente às coisas." ${ }^{35}$ Este argumento kantiano tem como alvo aqueles que acreditam possuir um acesso epistêmico privilegiado à experiência interior, aos fatos e processos internos da nossa consciência representacional. Os adeptos dessa tese internalista poderiam argumentar que, por mais que possamos e devamos ser céticos com relação aos objetos externos, nada nos autoriza a duvidar do conteúdo imanente e das mudanças de nossas próprias representações, o que atestaria a realidade do tempo, uma vez que essas representações ocorrem necessariamente no tempo. Kant afirmará que de fato o tempo possui uma realidade empírica, na qual todas as mudanças que experienciamos têm lugar. Contudo, não podemos nos valer desse argumento para provar uma suposta realidade transcendental ou absoluta do tempo. $\mathrm{O}$ fato de que a consciência que tenho de minhas próprias representações as dispõe numa sequência temporal não implica que o tempo seja uma determinação objetivamente inerente às coisas. Nietzsche observa a esse respeito que, segundo o argumento kantiano, seria necessário "distinguir entre o pensamento puro, que seria atemporal como o Ser parmenidiano, e a consciência desse pensamento, e esta última já traduziria o pensamento na forma da aparência, ou seja, da sucessão, da pluralidade e do movimento." ${ }^{36}$

Trata-se aqui justamente do argumento kantiano do fenomenismo da experiência interna. Contra aqueles que argumentam a favor da tese de que possuímos um acesso privilegiado às representações do sentido interno, Kant afirmará que a experiência interna, isto é, a consciência que temos de nós mesmos no fluxo de nossas representações, nos fornece apenas um fenômeno do mesmo gênero daqueles do mundo externo, o que significa que o conteúdo que acessamos pelo sentido interno não corresponde a nenhuma realidade que ultrapasse a realidade meramente fenomenal. O conceito central empregado por Kant nesse contexto é o de autoafecção, noção que caminha lado a lado com a tese da idealidade transcendental do tempo. Uma vez que a consciência que temos de nós mesmos e de nossas próprias representações emerge sob a forma do sentido interno (o tempo), ela não pode nos dar senão um fenômeno do sujeito, já que o sujeito em seu aspecto propriamente transcendental deve ser localizado numa dimensão atemporal e não condicionada pelas formas da 
sensibilidade. ${ }^{37}$ Nesse sentido, Parmênides poderia recorrer à tese kantiana e afirmar que a sucessão de nossas representações na consciência é apenas um fenômeno que não corresponde à verdadeira natureza do pensamento, do pensamento puro, idêntico a si mesmo e localizado numa dimensão atemporal assim como o próprio Ser.

Num segundo momento de sua argumentação, Nietzsche se servirá então de uma passagem decisiva de Spir contra a tese kantiana. Retomando o essencial do argumento referido acima de que as mudanças nas nossas representações são reais, o texto de Spir desenvolve essa ideia de um modo bastante sofisticado recorrendo a uma fenomenologia da representação de inspiração cartesiana:

É provável que Parmênides tivesse se servido dessa saída: aliás, dever-se-ia objetar contra ele o mesmo que A. Spir (Pensamento e realidade, p. 264) objeta contra Kant. "Agora, porém, é claro primeiramente que eu não posso saber nada de uma sucessão enquanto tal se eu não tiver ao mesmo tempo em minha consciência as partes que se sucedem. A representação de uma sucessão, portanto, não é ela mesma sucessiva; por conseguinte, ela é também totalmente distinta da sucessão de nossas representações. Em segundo lugar, a suposição de Kant implica absurdidades tão evidentes que é espantoso como ele pôde tê-lo ignorado. Segundo essa suposição, César e Sócrates não estão realmente mortos, eles continuam tão vivos quanto há dois mil anos e somente parecem estar mortos devido à configuração do meu "sentido interno". Homens futuros já vivem agora, e se eles ainda não aparecem como viventes é igualmente por culpa daquela configuração do "sentido interno". Aqui se coloca sobretudo a seguinte questão: como pode o começo e o fim da própria vida consciente, juntamente com todos os seus sentidos internos e externos, existir meramente na apreensão do sentido interno? O fato é que não podemos de modo algum negar a realidade da mudança. Se a jogarmos pela janela, ela surge novamente pelo buraco da fechadura. Que se diga: "simplesmente me parece que os estados e as representações mudam" - entretanto, essa aparência mesma é algo objetivamente existente e nela a sucessão possui, sem dúvida alguma, realidade objetiva; nela, as coisas realmente se seguem umas às outras. - Ademais, deve-se notar que toda a crítica da razão só pode estar fundamentada e justificada a partir do pressuposto de que nossas representações mesmas nos aparecem como elas são. Pois, caso as representações também nos aparecessem diferentemente de como elas são realmente, não se poderia fazer afirmações válidas acerca delas, ou seja, não se poderia realizar nenhuma teoria do conhecimento e nenhuma investigação transcendental. Ora, está fora de dúvida que nossas próprias representações nos aparecem como sucessivas. ${ }^{38}$

Abstraindo-se alguns detalhes em certo sentido marginais, a parte ad hominem do argumento e alguns exageros retóricos presentes no texto, podemos dizer que o argumento filosófico principal desta passagem é o seguinte: ao 
dizer que meus estados de consciência e minhas representações me aparecem como sucessivos e mutáveis, sou obrigado a aceitar que essa aparência mesma possui uma realidade objetiva enquanto estado de consciência - realidade da qual não podemos abstrair a temporalidade sem contradizer radicalmente a evidência fenomenológica mais elementar do processo do representar. Nesse sentido, a estrutura da argumentação em questão é semelhante à estrutura do cogito cartesiano, e o incisivo apelo de Spir ao conteúdo factual da representação como certeza imediata da consciência em analogia ao método filosófico de Descartes é prova dessa semelhança. Há aqui um apelo à fenomenalidade radical da consciência representacional, que é levada a seus limites, e à evidência de sua forma constitutiva. Ora, por mais que Nietzsche (sobretudo em seu período de maturidade) se mostre profundamente cético quanto ao apelo filosófico a certezas imediatas e fatos da consciência, de onde provém sua crítica incisiva tanto ao cogito cartesiano (que apela à imediaticidade do pensar) quanto à filosofia da vontade de Schopenhauer (que apela à imediaticidade do querer), essa "forma minimal" 39 de argumentação fenomenológica a favor da realidade objetiva do tempo não parece ofender sua prudência cognitiva. Ela nada afirma sobre um suposto sujeito subjacente às mudanças e oferece a possibilidade de uma "interpretação eliminativa" 40 a favor de uma tese com a qual Nietzsche parece estar de acordo desde muito cedo. Com efeito, o que é considerado nessa argumentação não é o cogito tal como o compreenderá Nietzsche mais tarde, isto é, o conteúdo de um ato de consciência entendida enquanto substância pensante, mas sim a forma da cogitatio, a saber, sua forma temporal enquanto estrutura imanente a toda representação possível. De acordo com este argumento, o modo temporal das representações, o fluxo da consciência, implica a realidade objetiva do tempo. Trata-se aqui, portanto, de uma constatação fenomenológica de que à essência de toda cogitatio pertence um tempo que é constitutivo da cogitatio ela mesma e que não pode ser dela abstraído. Assim, a temporalidade não é um atributo acidental do pensamento e da representação, que viria se somar a eles na medida em que se tornam fenômenos para a consciência; antes, ela é uma de suas determinações mais essenciais. O aparecer sucessivo e em constante mudança de dados sensíveis imanentes na atividade do representar é fenomenologicamente indubitável. Por conseguinte, na medida em que a sucessão e a mudança das representações possuem realidade objetiva; na medida em que, no próprio aparecer das representações, uma coisa se segue realmente à outra, não estamos autorizados 
a negar a realidade do tempo. ${ }^{41} \mathrm{Com}$ isso, a tese kantiana da idealidade transcendental do tempo estaria refutada.

Dando ainda um passo além no sentido de uma análise mais profunda do argumento, podemos observar o seguinte: o primeiro ponto da crítica de Spir citada por Nietzsche na passagem acima - isto é, que não podemos saber nada de uma sucessão se não tivermos ao mesmo tempo na consciência as partes que se sucedem, e que, portanto, a representação de uma sucessão não é ela mesma sucessiva e é por conseguinte distinta da sucessão de nossas representações - se opõe à afirmação de Kant de que "a sucessão das representações não seria de modo algum distinta da nossa representação da sucessão". ${ }^{42}$ Para Spir, a sucessão das representações não pode ser identificada com a representação de sua sucessão. Ao contrário, a representação de uma sucessão só é possível na medida em que uma sucessão de representações nos é anteriormente dada de modo objetivo, e cuja realidade precisamos afirmar de antemão para que possamos obter uma representação ulterior do processo, o que significa: se não afirmamos a existência da sucessão, ou seja, a existência de um movimento real de nosso pensamento, nenhuma representação da sucessão é possível.

Além disso, Kant não teria deixado claro, em sua distinção fundamental entre coisa em si e fenômeno (representação), o que ele entende por fenômeno e qual realidade ele concede ao mundo dos fenômenos. Este teria sido seu erro básico, que o teria conduzido à falsa concepção da irrealidade do tempo.

Ele definiu os fenômenos por toda parte como meras representações, mas ele não distinguiu estas duas coisas totalmente heterogêneas: 'ser uma representação' e 'ser meramente representado' ou 'existir meramente na representação.' Ele não distinguiu a representação mesma, como um processo objetivo ou como objeto, daquilo que é nela reproduzido ou representado. ${ }^{43}$

Este é um ponto fundamental para o argumento de Spir: na medida em que a existência da representação ela mesma, e não daquilo que é nela representado, não pode ser negada, tampouco podemos negar a existência objetiva de uma sucessão temporal, pois as representações ocorrem necessariamente no

41 Esse mesmo argumento comparecerá novamente na obra posterior de Nietzsche, inicialmente no contexto das notas de 1881 que apresentam uma versão alternativa do cogito a favor da realidade da mudança e do caráter global da representação como característica essencial do Ser (cf. principalmente o fragmento N 188111 [330], mas também: 11[321], [324] e [325]. Para uma análise do argumento central dessas notas e de sua referência a Spir, cf. Mattioli, 2011, pp. 248-254). Posteriormente, esse argumento comparecerá no contexto de uma das formulações da tese do eterno retorno (cf. N 1885 36[15]. A esse respeito, ver ainda Small, 1994, p. 100).

42 Spir, 1873, I, p. 264.

43 Ibidem, p. 266. 
tempo. Ou seja, a temporalidade do processo de representação enquanto processo objetivo não pode ser descartada.

\section{V}

Mas Spir, movido pelo que talvez seja uma certa "piedade filosófica" ou simplesmente pelo princípio de caridade interpretativa, concede razão a Kant em dois pontos no que concerne à tese da idealidade transcendental do tempo:

1) o primeiro é que Kant teve razão ao afirmar que "o tempo em si" não é algo real, pois este seria uma mera abstração das sucessões que nos são realmente dadas e não poderia ser representado sem elas. Um "tempo em si" no sentido de um tempo vazio, no qual nenhuma mudança ocorresse, é uma mera abstração e nesse sentido algo irreal ${ }^{44}$ Este argumento, que se encontra na sequência do trecho retirado pelo jovem Nietzsche do primeiro volume da obra, já antecipa uma segunda crítica de Spir à compreensão kantiana do tempo, presente no segundo volume, e que não se refere mais à tese da idealidade transcendental, mas sim à tese do apriorismo do tempo. Nietzsche se refere a esta crítica nos fragmentos 35[56] e 35[61] de 1885, nos quais ele cita Spir: "o tempo não é dado a priori - Spir 2, p. 7"; 45 e na sequência: "“o assim chamado tempo, uma mera abstração, nem existente objetivamente, nem um modo de representação necessário e originário do sujeito' $<$ Spir $>2$. p. 15. ${ }^{\prime 46}$ Se não contextualizados, estes fragmentos podem levar a falsas interpretações da posição nietzscheana acerca do problema. O leitor desatento pode ser tomado pela impressão de que Nietzsche se serve aqui de uma citação de Spir para sustentar a ideia de que o tempo, na medida em que é uma mera abstração, na medida em que não existe nem objetivamente nem como forma a priori de nossa faculdade cognitiva, não possui nenhuma realidade que ultrapasse a esfera da consciência empírica, sendo não exatamente uma forma da representação, mas sim um produto dela. Porém, essa seria uma leitura profundamente equivocada. ${ }^{47}$ Como mencionado, Nietzsche se refere aqui à crítica de Spir à tese kantiana do caráter a priori do tempo. Spir concede a Kant que, se entendido como um tempo vazio (e esta é justamente a consequência da tese da Estética Transcendental que entende o tempo como forma pura a priori dos fenômenos), este não pode ser real. O que Nietzsche chama

47 Essa é a leitura, por exemplo, de Erwin Schlimgen em seu livro "Nietzsches Theorie des Bewußtseins" (cf. Schlimgen, 1999, p. 83). 
de "tempo" ao citar Spir no fragmento 35[61] referido acima não é, portanto, o tempo que nos é dado na experiência da sucessão e da mudança, mas sim o tempo como conceito abstrato, como forma pura, referido pela expressão "o assim chamado tempo". Este assim chamado tempo é, nesse contexto, o tempo da Estética Transcendental kantiana, do qual abstraímos todo conteúdo, ou seja, toda sucessão e toda mudança possíveis. Trata-se do tempo vazio. Ora, um tal tempo vazio, no qual não há sucessão ou mudança, não existe nem para Nietzsche nem para Spir.

O ponto central do argumento de Spir pode ser resumido da seguinte forma: Kant afirma que o tempo é uma representação necessária que está na base de toda intuição. Por conseguinte, poderíamos extrair todo fenômeno dado na intuição, e o tempo permaneceria, como forma pura a priori. Poderíamos abstrair de toda sucessão e de toda mudança no tempo, mas o tempo mesmo jamais poderia ser suprimido. ${ }^{48}$ Segundo Spir, o erro de Kant consiste em primeiro lugar na tentativa de estabelecer um paralelismo estrito entre as intuições do tempo e do espaço. Para o reformulador da filosofia crítica, é verdade que as coisas espaciais nos são dadas somente por intermédio de uma forma do sentido externo, ou para dizer de outro modo: as representações espaciais são construídas na intuição. Mas esse não é de modo algum o caso no tocante às sucessões temporais. Estas nos são dadas real e imediatamente e sua realidade objetiva não pode ser negada, ao passo que a existência das coisas no espaço permanece sempre duvidosa. ${ }^{49}$ Em segundo lugar, o tempo não é, diferentemente do espaço, uma forma geral da representação ou mesmo uma representação geral da qual poderíamos abstrair o conteúdo dado. Este parece ser o ponto central do argumento, ao qual já nos referimos acima. Segundo Spir, podemos efetivamente nos representar um espaço vazio, mas um tempo vazio é, para ele, algo inconcebível: "um tempo vazio, isto é, um tempo no qual nada ocorre, no qual não se dão nenhum evento e nenhuma sucessão, não pode ser representado." ${ }^{50} \mathrm{Um}$ tal tempo vazio é irrepresentável pois o tempo não é senão a sucessão mesma das mudanças, por meio da qual ele pode ser medido: "além das sucessões, nada se pode conceber que poderia servir como medida do tempo. Por essa razão, o tempo desaparece completamente se abstraímos das sucessões reais." ${ }^{11}$

48 Cf. Kant, CRP A31/B46, e Spir, 1877, II, p. 7.

49 Cf. Spir, 1877, II, p. 5.

50 Ibidem, p. 7.

51 Ibidem, p. 8. 
A conclusão de Spir não poderia ser outra: um "tempo" no qual nada ocorre não é tempo; o "tempo em geral", como forma pura sem conteúdo é, portanto, uma representação vazia, que resta como mera abstração após suprimirmos pelo pensamento as sucessões reais. A passagem citada por Nietzsche no fragmento 35[61] de 1885 se refere à conclusão dessa argumentação, onde Spir afirma "que o assim chamado tempo é uma mera abstração e não pode ser visto nem como algo existente objetivamente, nem como um modo de representação necessário e originário no sujeito". ${ }^{52}$

2) O segundo ponto com relação ao qual Spir entende que a tese kantiana da irrealidade do tempo provém de uma intuição legítima diz respeito ao fato de que o conceito que temos da essência incondicionada do mundo não comporta a possibilidade da mudança e, portanto, da realidade objetiva do tempo. (É nesse sentido que, para Nietzsche, a filosofia transcendental, ao afirmar o caráter puramente fenomenal e em certo sentido "ilusório" do mundo da experiência, seria uma versão moderna e renovada das teses dos eleatas.) Para Spir, o tempo não pode pertencer à coisa em si, pois a coisa em si, segundo o conceito que temos dela (derivado do princípio de identidade), não pode estar submetida à mudança. O que teria faltado a Kant é, segundo seu crítico, a sutileza teórica na elaboração da distinção entre fenômeno e coisa em si. Ao supor somente dois tipos de "objetos", correspondentes a dois níveis ontológicos distintos: as coisas em si, por um lado, que existem independentemente da representação, e as coisas fenomênicas, por outro, existentes na representação e portanto sem realidade objetiva, Kant teria ignorado um terceiro tipo ou nível ontológico: trata-se da representação ela mesma, que existe realmente e de modo objetivo, mas não como coisa em si. Neste nível ontológico, ao qual pertence ainda o sujeito cognoscente, a temporalidade tem uma existência objetiva e a realidade da mudança não pode ser negada. ${ }^{53}$

\section{VI}

Nietzsche, ao acatar a tese de Spir da realidade do tempo e da mudança, rejeitará por sua vez o pressuposto de um nível ontológico superior que corresponderia ao Ser de Parmênides ou à coisa em si kantiana e no qual nosso conceito de incondicionado poderia ser objetivamente instanciado. Em vez disso, ele entenderá esse conceito como uma ficção regulativa necessária que responde aos interesses vitais de certos complexos orgânicos com vistas à 
constituição e ao desenvolvimento do que poderíamos chamar de operações e disposições intencionais, que tornarão possível o desenvolvimento de suas capacidades cognitivas-adaptativas. Sua aposta ontológica, portanto, é no caráter temporal e mutável imanente à dimensão do devir, que Spir remete ao nível ontológico intermediário dos processos representacionais.

Em uma série de fragmentos de $1881,{ }^{54}$ numa confrontação direta com Spir, Nietzsche procura entender os processos intencionais relativos à dimensão da representação como aquilo que há de mais certo e mais essencial no universo. Essas notas parecem ser esboços do que virá a se configurar mais tarde como a hipótese das vontades de poder enquanto processos de interpretação. Nessa série de fragmentos, Nietzsche concede ao fato (constatável fenomenologicamente) de que há representações o status de certeza fundamental (em analogia ao cogito cartesiano), e a capacidade de representação é vista como uma característica primitiva do próprio Ser. Desse modo, o devir e a temporalidade, atributos essenciais das operações ligadas à representação, são considerados como características essenciais do Ser compreendido em seu aspecto global, ao passo que a permanência e a identidade são vistas como ficções necessárias para que a representação possa dar origem a um conteúdo cognitivamente determinável e, portanto, assimilável. Sem essa ficção jamais poderia surgir algo como o pensamento: "o pensamento seria impossível se ele não desconhecesse fundamentalmente a essência [...]: ele precisa afirmar a substância e o idêntico, pois um conhecimento daquilo que está absolutamente em fluxo é impossível." ${ }_{55}$ Nesse sentido, segundo Nietzsche, é preciso que complexos orgânicos criem descontinuidades no fluxo contínuo dos acontecimentos para que eles possam perceber objetos, substâncias, relações causais; é preciso que eles sejam capazes de reconhecer o mesmo diante do não idêntico, de abstrair da singularidade, da pluralidade e da mudança para identificar fenômenos e se acomodarem ao mundo, tornando assim possíveis sua sobrevivência e evolução. Essa seria uma exigência de conservação da vida que só pôde realizar-se com o surgimento, numa fase primitiva da evolução desses complexos orgânicos, de um princípio cognitivo que age de modo regulativo fixando como identidade aquilo que se encontra em constante mudança, tornando possível assim a percepção do mundo como um mundo de objetos "ideais" estáveis.

54 Cf. N 1881 11[321], [324], [325], [329], [330].

$55 \mathrm{~N} 1881$ 11[330]. Para uma análise mais aprofundada da argumentação presente nestas notas, cf. Mattioli, 2011, pp. 248-254. 
Esta tese, que aparece modestamente nas obras publicadas e em afirmações mais temerárias nos fragmentos póstumos, é desenvolvida com mais clareza sobretudo a partir do período intermediário. É em "Humano, demasiado humano", com o programa de uma filosofia histórica aliada às ciências empíricas, que Nietzsche articula pela primeira vez de modo claro sua teoria do devir com sua crítica à filosofia transcendental, o que culmina numa teoria do erro segundo a qual nosso conceito de substância falsifica sistematicamente a realidade do devir. Sua crítica tem como alvo principalmente as filosofias de Kant e Schopenhauer, assim como o programa de renovação da filosofia crítica levado a cabo por Spir. Sobretudo os aforismos 2 ("Defeito hereditário dos filósofos"), 16 ("Fenômeno e coisa em si") e 18 ("Questões fundamentais da metafisica") deixam clara a intenção de Nietzsche de transformar os conceitos transcendentais em condicionantes históricos ligados à evolução dos seres orgânicos em geral, da espécie humana em particular, e de suas instituições sociais e culturais. Mas o ponto central no que concerne à crítica a Spir e ao seu conceito do incondicionado encontra-se no aforismo 18, que procura reinterpretar o princípio de identidade, que em Spir assume a função de lei originária do sujeito cognoscente (no sentido transcendental), como uma função orgânica:

Quando algum dia se escrever a história da gênese do pensamento, nela também se encontrará, sob uma nova luz, a seguinte frase de um lógico eminente: "A lei universal do sujeito cognoscente consiste na necessidade interior de reconhecer cada objeto em si, em sua própria essência, como um objeto idêntico a si mesmo, portanto existente por si mesmo e, no fundo, sempre igual e imutável, em suma, como uma substância". Também essa lei, aí denominada "originária", veio a ser - um dia será mostrado como gradualmente surge essa tendência nos organismos inferiores. ${ }^{56}$

Convertida em herança atávica de estágios primitivos da evolução dos organismos e contraposta à tese do devir universal, a necessidade subjetiva (cujo caráter cognitivamente imperativo Nietzsche reconhece sem receios) de identificar objetos empíricos como entidades discretas e idênticas a si mesmas perde sua validade objetiva, de onde emerge um ficcionalismo generalizado. Nesse cenário teórico, o papel da filosofia não pode mais ser definido em termos justificatórios, no sentido de estabelecer as condições universais de verdade e de validade de nossos juízos. Ela tampouco pode continuar reivindicando para si a autoridade epistêmica para legitimação de qualquer tipo de

56 HH 18. Infelizmente não há espaço aqui para uma análise mais detalhada do contexto geral de "Humano" e de sua confrontação com a filosofia transcendental, principalmente de Spir. Para uma discussão mais detida desses pontos, cf. Lopes, 2008, Capítulo II, Sessão 3; e D’lorio, 1993, pp. 270-276. 
conhecimento a priori ou metafísico. Pelo contrário, sua tarefa agora deve incluir um programa de desconstrução da força normativa das convicções metafísicas mediante uma investigação genealógica de sua origem, do seu significado e de sua função vital. Ao pretender mostrar, com auxílio das ciências empíricas, "que todo conceito de incondicionado corresponde a uma ficção regulativa que teve sua origem nas formas orgânicas primitivas e foi transmitido através dos mecanismos de hereditariedade", ${ }^{57}$ a filosofia histórica de Nietzsche se compromete com um certo naturalismo que contesta, em seu fundamento, o tipo de transcendentalismo robusto que Spir almejava ressuscitar.

\section{Referências}

CLARK, M.; DUDRICK, D. "The Naturalisms of Beyond Good and Evil". In: $A$ Companion to Nietzsche. Ed. K. Ansell-Pearson. Oxford: Blackwell, 2006. pp. 148-167. D'IORIO, P. "La superstition des philosophes critiques. Nietzsche et Afrikan Spir". Nietzsche-Studien, 22, pp. 257-294, 1993.

GREEN, M. S. "Nietzsche and the transcendental tradition". Illinois: University of Illinois Press, 2002.

HELMHOLTZ, H. "Handbuch der physiologischen Optik". In: Allgemeine Encyklopädie der Physik. Hrg. von Gustav Karsten. Leipzig: Leopold Voss, 1867. IX Band. KANT, I. "Crítica da razão pura" [CRP]. Tradução de Manuela Pinto dos Santos e Alexandre Fradique Morujão. Lisboa: Fundação Calouste Gulbenkian, 2001.

LANGE, F. "Geschichte des Materialismus und Kritik seiner Bedeutung in der Gegenwart". Iserlohn: J. Baedeker, 1866.

LOPES, R. "A almejada assimilação do materialismo": Nietzsche e o debate naturalista na filosofia alemã da segunda metade do século XIX". Cadernos Nietzsche, São Paulo, n. 29, pp. 309-352, 2011.

LOPES, R. "Ceticismo e vida contemplativa em Nietzsche". Tese (Doutorado). Belo Horizonte, UFMG, 2008.

MATTIOLI, W. "Do idealismo transcendental ao naturalismo: um salto ontológico no tempo a partir de uma fenomenologia da representação". Cadernos Nietzsche, São Paulo, n. 29, pp. 221-270, 2011.

MATTIOLI, W. "Metáfora e ficcionalismo no jovem Nietzsche”. Revista Trágica, Rio de Janeiro, Vol. 3, n. 2, pp. 39-60, $2^{\circ}$ Semestre de 2010 [online]. Disponível em: http:// www.tragica.org/. (Acessado em: 31/07/2013)

MEIJERS, A. "Gustav Gerber und Friedrich Nietzsche. Zum historischen Hintergrund der sprachphilosophischen Auffassung des frühen Nietzsche”. Nietzsche-Studien, 17, pp. 369-390, 1988. 
MEIJERS, A.; STINGELIN, M. "Konkordanz zu den wörtlichen Abschriften und Übernahmen von Beispielen und Zitaten aus Gustav Gerber: Die Sprache als Kunst (Bromberg 1871) in Nietzsches Rhetorik-Vorlesung und in 'Ueber Wahrheit und Lüge im aussermoralischen Sinne"”. Nietzsche-Studien, 17, pp. 369-390, 1988.

MEYER, M. "Nietzsche's Naturalism and the Falsification Thesis". In: Nietzsches Wissenschaftsphilosophie. Hintergründe, Wirkungen und Aktualität. Ed. H. Heit, G. Abel, M. Brusotti. Berlin/Boston: Walter de Gruyter, 2012.

NIETZSCHE, F. "Humano, demasiado humano". Tradução de Paulo César de Souza. São Paulo: Companhia das Letras, 2005.

NIETZSCHE, F. “Sämtliche Werke. Kritische Studienausgabe” [KSA]. Herausgegeben von Giorgio Colli und Mazzino Montinari. 15 Bände. Berlin: Walter de Gruyter, 1999. NIETZSCHE, F. "Werke. Kritische Gesamtausgabe" [KGW]. Herausgegeben von Giorgio Colli und Mazzino Montinari. Berlin/New York: Walter de Gruyter, 1995.

REUTER, S. "Reiz. Bild. Unbewusste Anschauung. Nietzsches Auseinandersetzung mit Hermann Helmholtz' Theorie der unbewussten Schlüsse in Über Wahrheit und Lüge im aussermoralischen Sinne". Nietzsche-Studien, 33, 2004.

RICCARDI, M. "Der faule Flecke des Kantischen Kriticismus. Erscheinung und Ding an sich bei Nietzsche". Basel: Schwabe, 2009.

SCHLIMGEN, E. "Nietzsches Theorie des Bewußtseins". Berlin. New York: Walter de Gruyter, 1999.

SMALL, R. "Nietzsche, Spir, and Time". Journal of the History of Philosophy, 32, 1, pp. 85-102, 1994.

SMALL, R. "Time and Becoming in Nietzsche's Thought". London/New York: Continuum, 2010.

SPIR, A. "Denken und Wirklichkeit. Versuch einer Erneuerung der kritischen Philosophie". Leipzig: J. G. Findel, 1873. (2. Edição: 1877). 